\title{
A personal view of the Internet
}

\author{
By Mary Page
}

\section{A beginning overview of the Net}

J ust over three years ago, William A. Britten's excellent article on Bitnet and the Internet appeared in these pages. ' For many librarians, even those familiar with the basic concepts and terminology, Britten provided the first real overview of the network. For me, it was the first time I made the connection between the NREN and the e-mail that I was just beginning to use in my daily work. Using Britten's "networkography" to venture even further, I was encouraged to take a few tentative steps into Networkland. Since then the network's resources have grown exponentially, and several new tools have been introduced to help us find our way. With so many changes, it might be useful to review briefly the network's capabilities, its development, and what we should keep an eye on for the future.

\section{Internet capabilities}

If you have never used the Internet, here is a brief description of its three main capabilities: electronic mail, remote login, and file transfer.

E-mail. In its most basic form, electronic mail, or e-mail, is electronic messaging between individuals. I use e-mail to communicate with the people I work with every day as well as with librarians at other institutions. E-mail provides a fast and easy way to communicate. I may not see my boss for days, but I still feel that we are in close contact, because I can let her know what I'm working on and ask questions and get quick answers without the frustrations of telephone tag.
In addition to being able to communicate with another individual, it is easy to send a message to a group of people. This can be a remarkably efficient way to share information or to get committee work done.

Typically, e-mail messages are informal and that is one of the reasons why it makes communication so fast. Most people are comfortable firing off quick comments or questions without composing a formal memo. While the informality is one of the most appealing features of e-mail, it can also be one of its pitfalls. Almost everyone learns the hard way that sometimes it is best to resist the temptation to respond immediately to something you find disagreeable. These are new frontiers, and the etiquette for electronic communication is still evolving.

Another way e-mail is used is to access what are commonly referred to as LISTS. The lists on the network are forums for online discussions on every conceivable topic: there are lists for botanists, medievalists, cat lovers, gays, tornado watchers, and vegetarians. There are numerous library lists: there are lists devoted to cataloging and authority control, serials, interlibrary loan, library automation, library administration, and virtually every automated system has a list for users to discuss problems and share information.

The lists are really an incredible resource. At Rutgers we are installing the Innopac serials control system, and to gather information I sent a query to the Innopac list asking how other libraries have approached installation in a multisite setting. The response was wonderful! A dozen librarians from all over the country offered all sorts of advice and relayed personal experiences. Nothing drives home the concept of "global village" faster. 


\section{Glossary of Internet terminology}

Archie. A database and related programs that allow users to search for information stored at various remote sources.

Backbone. A high-speed connection within a network which connects smaller (and slower) networks. The NSFNet is the backbone network of the Internet in the U.S.

Client. A program on a local computer which requests services from a remote computer. Client/server software splits up the tasks of retrieving information from remote computers. The "client" handles the interface and display operations on the local computer, while the "server" focuses on information retrieval from the source computer. See server.

E-mail. Electronic mail; online messaging between computer users.

E-serial (or e-journal). A periodical distributed in electronic form.

FTP (File Transfer Protocol). Allows users to transfer files from a remote computer to their host computer.

Gopher. Client/server software providing improved, keyword access to Internet resources.

Host. The computer on which you have interactive sessions, or which serves as your source of networked services.

Internet. The international network of networks based on the TCP/IP protocol.

OSI (Open Systems Interconnect). A set of standards for computer connections. In some ways it "competes" with TCP/IP, which is the most common protocol in the U.S.

Protocol. Rules which govern the transmission and receipt of data.

Server. A program that provides services, usually access to a database or data files, when requested from a user at a remote computer. See client.

TCP/IP (Transmission Control Protocol/Internet Protocol). The standard protocol for transmitting data over the Intemet.

Telnet. Provides a connection to a remote computer over the Internet, or remote login.

WAIS (Wide-Area Information Servers). Client/server software for searching and retrieving information from various databases.

Source: Roy Tennant, Jobn Ober, and Anne G. Lipow, Crossing the Internet Threshold: An Instructional Handbook (Berkeley, Calif.: Library Solutions Press, 1992).
Remote login. The second major capability of the Internet is remote login, which is the ability for a user on one computer to connect with another computer at a remote site. On the Internet users refer to telnetting into another computer, because the access command is telnet. (Telnet is not to be confused with Telenet, the telecommunications service that allows access to online databases through a modem with a local call.) Once you have telnetted to another computer, you can use the remote system as if you were sitting at one of its hardwired terminals. Through the Internet hundreds of online library catalogs can be accessed, as well as information for educators on NASA programs, weather and meteorological information, geographic data, headline news, stock market reports, and Supreme Court decisions.

File transfer protocol. The third major feature of the Internet is the File Transfer Protocol (FTP) which is the ability to transfer data files from one computer to another. FTP is similar to telnetting in that you access a remote computer. The difference is that FTP connections are used specifically to locate and transfer data files which may be software programs, text files, or any kind of file that can be stored on a computer. In many cases, these files are complete documents which can be transferred from a remote computer into a file on your mainframe computer, then downloaded to your $\mathrm{PC}$ and manipulated through word processing software. Examples of the kinds of documents that are available include lyrics to songs, Shakespeare sonnets and plays, and any number of instructional guides to the Internet itself:

The three major services on the Internetelectronic mail, remote login, and file transfer-make a wealth of resources available to anyone with network access. However, most new users find the network awkward to use. There are a number of commands to memorize, and most experienced users will tell you that they've found themselves hopelessly lost at one time or another. In fact, the resources on the Internet have been described as a vast library without access points. You really have to know what you're looking for and where to find it to successfully negotiate the Internet.

\section{Internet navigation tools}

Fortunately, help is on the way. A number of new services are being developed to make the Internet easier to use and searching more sophisticated. 


\section{Receive first class treatment at Ballen...}
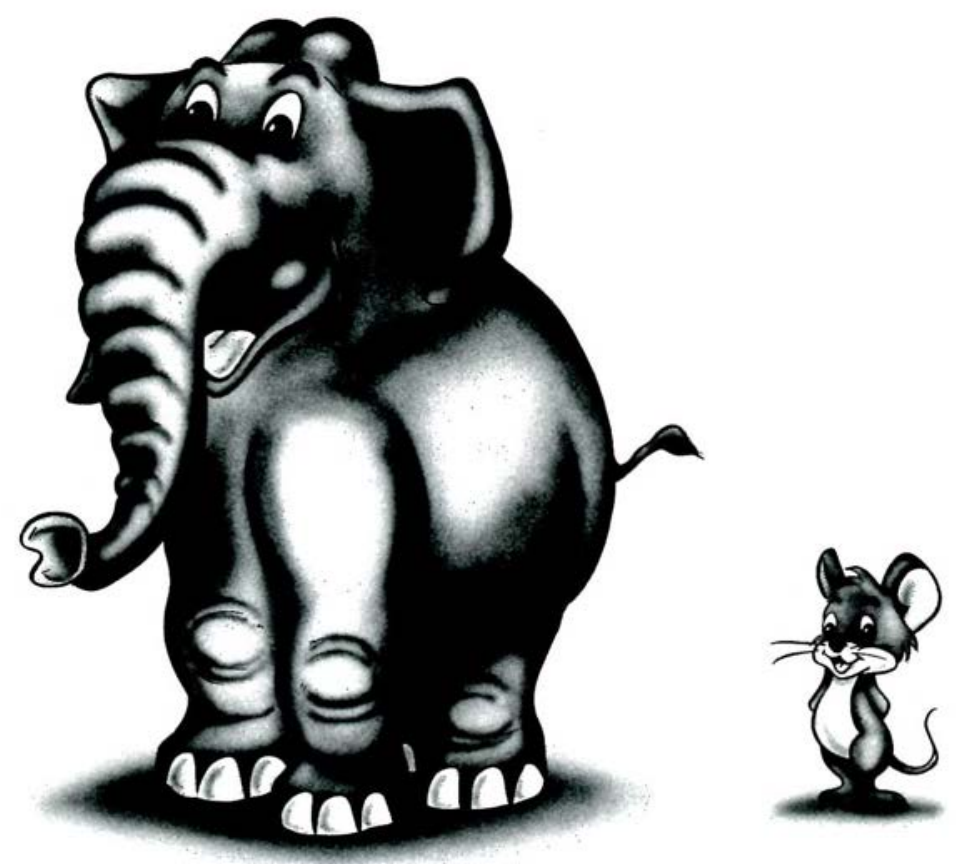

\section{no matter what your size.}

Whether your order is for a thousand books or just one, whether you are a prestigious university, medical school, or a little-known junior college, every Ballen customer receives our legendary one-to-one customized service.

That means you'll have a personal Ballen customer service representative to answer questions, report status and solve problems. You'll have a specific location in our staging area for maximum quality control. You'll have instant access to important information through BallenNet ${ }^{\mathrm{TM}}$, our interactive on-line service for order entry data and current order status. Even direct telephone access to a Ballen corporate officer, if necessary.

And despite our elephantine inventory of over 100,000 titles, with thousands of books shipped every week, our return rate squeaks in at less than $1 \%$ - the industry's lowest.

Find out how you can reap the big benefits of Ballen's personal service. Call Toll-Free (800) 645-5237

or Fax (516) 864-5850.

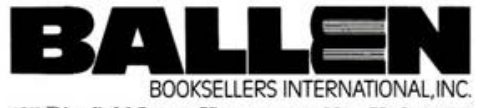




\section{Education}

\section{Research Just Became Easier With the New ED-INFO CD}

The ED-INFO CD is a comprehensive national statistical data base containing information on all public elementary and secondary schools and school districts in the United States.

Compiled from data obtained from Nation Center for Education Statistics. (Department of Education), the ED-INFO CD contains three categories of information:

1. General descriptive information (includes name, address, phone number, and type of locale.)

2. Basic statistics (includes numbers of students and staff, and associated data.)

3. Fiscal data (includes revenues and current expenditures.)

The data base contains three levels of information:

1. Schools

2. School Districts/Agencies

3. State (non-fiscal, fiscal)

The three data files within ED-INFO can be used separately or in conjunction with one another to determine:

1. Size of school and pupil-teacher ratio

2. Size of school district

3. State expenditure for education and per pupil expenditure

4. Racial/ethnic composition

5. Students by grade level and number of graduates

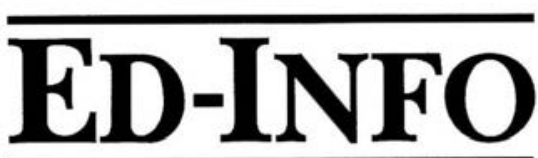

EDUCATION DATA DISC

\section{Data Facts}

a) Data are obtained from administrative records maintained by State Education Agencies (SEAs).

b) Public school file contains data on over 84,000 schools. Census finance data is also included.

c) Public education agency (districts) universe file contains 17,000 records.

d) State file contains fall membership by grade; fulltime equivalent teachers and other staff by major employment categories. Includes revenues by source; current expenditures by major function; and per pupil expenditures.

\section{ED-INFO is the essential all-in-one education research tool!}

To order the ED-INFO CD, for your scbool or library, send your cbeck or money order for $\$ 495$ to:

CTMG Publishers

1501 Wilson Blvd.

Suite 1110

Arlington, VA 22209

Alternate methods of payment

aill school P.O. number

Bill my a vISA a MasterCard a American Express

Account No Exp.Date

Signature

$\square$ Bill me (Sorry, we can only extend billing privileges when shipping to a school address.) 
tion. The legislation is quite vague in describing what the NREN user community will be, raising several questions: Will the Internet continue to be publicly financed and operated? Or will it evolve into a component of the telecom-

\section{List of network providers}

(Selected from the NSF Network Provider Service List)

NSF Network Service Center (for information only), 10 Moulton Street, Cambridge, MA 02138; (617) 873-3400.

Alternet. U.S. and international, (800) 4UUNET3.

ANS. U.S. and international, (313) 663-7610 (Joel Maloff).

JVNCNet. U.S. and international, (800) 35TIGER (Sergio Heker, Allison Pihl).

NEARNet. Northeastern U.S., (617) 873-8730 (John Curran).

NYSERnet. New York, (315) 443-4120 (Jim Luckett).

PREPnet. Pennsylvania, (412) 268-7870 (Tom Bajzek).

PSCnet. Eastern U.S., (412) 268-4960 (Eugene Hastings).

PSINet. U.S. and international, (800) 82PSI82.

SprintLink. U.S. and international, (703) 904-2230 (Bob Doyle).

Ed note: Although we do not bave reports from anyone who bas used this service, we have just learned of DELPHI, an online service provided by General Videotex Corporation in Cambridge, Massacbusetts. DELPHI offers two membership plans, connection to the Internet, and an online support service which includes a message forum, guidebooks, downloadable sofiware, and information files. For information call: (800) 5444005 or (617) 491-3342. munications industry and be marketed as a service? While it is generally acknowledged that network capacity must be expanded and improved, it remains to be seen just how development will proceed. Librarians have been pioneers on the Internet, aggressively exploring its resources and sharing what we find. While there are some persuasive arguments to be made for privatization, much of the network development to this point has been through volunteer efforts, creating a loosely organized community that values cooperation and the sharing of information. There is clear potential for conflict with proprietary interests. Librarians do need to take a leadership role in the NREN's development; perhaps the best way is to become accomplished Internet explorers who share what we find with our constituencies.

\section{Notes}

"William A. Britten, "BITNET and the Internet: Scholarly networks for librarians," College and Research Libraries News 51:2 (February 1990): 103-07.

'John Markoff, "Building the electronic superhighway," The New York Times (January 24 , 1993): sec. 3, p. 1.

\section{Resources}

Dern, Daniel P. "Plugging into the Intemet: The range of options for access is almost as broad as the range in Internet resources." BYTE 17:10 (October 1992): 149-56.

Kesselman, Martin. "CD-ROM/online update: The Internet." Wilson Library Bulletin 66:7 (March 1992): 76-78.

Krol, Ed. The Whole Internet: User's Guide and Catalog. Sebastopol, Calif:: O'Reilly and Associates, 1992.

Lukanuski, Mary. "Help is on the WAIS." American Libraries 23 (9) (October 1992): 74244.

Malinconico, S. Michael. "What librarians need to know to survive in an age of technology." Journal of Education for Library and Information Science 33 (3) (Summer 1992): 226-40.

Polly, Jean Armour. "Surfing the Internet: An introduction." Wilson Library Bulletin 66:10 (June 1992): 38-42.

Tennant, Roy, John Ober, and Anne G. Lipow. Crossing the Internet Threshold: An Instructional Handbook. Berkeley, Calif.: Library Solutions Press, 1992. 


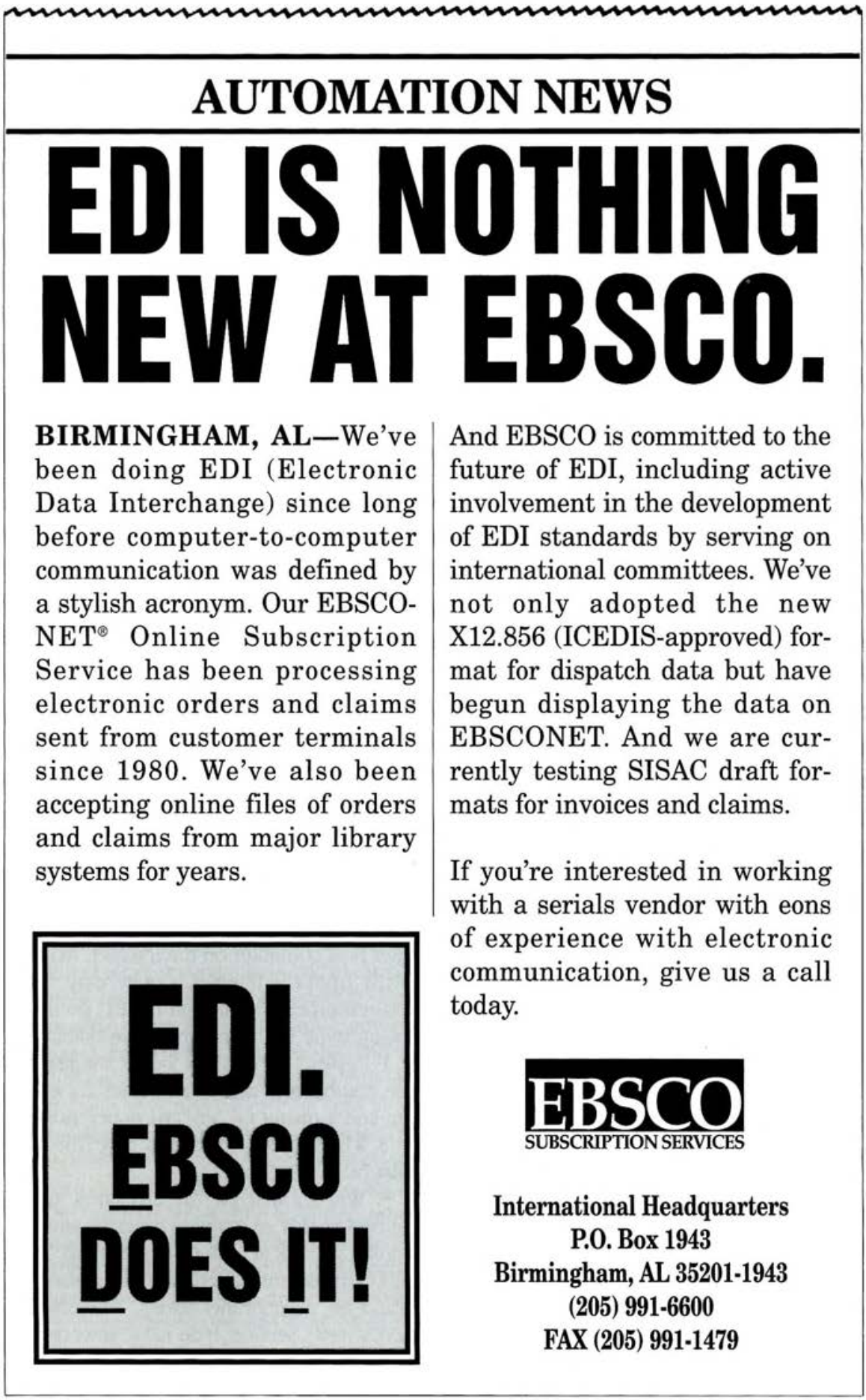

